MENDONÇA, F.V.S.; MENEZES, J.B.; GOIS, V.A.; GUIMARÃES, A.A.; NUNES, G.H.S.; MENDONÇA JÚNIOR, C.F. Efeito do retardamento da colheita, na qualidade e na vida útil do melão Orange Flesh. Horticultura Brasileira, Brasília, v.22, n.1 p. 35-38, jan-mar 2004.

\title{
Efeito do retardamento da colheita, na qualidade e na vida útil do melão Orange Flesh
}

\author{
Fábio Vinícius de S. Mendonça; Josivan B. Menezes; Vilson A. de Gois; Adriana A. Guimarães; Glauber \\ Henrique de S. Nunes; Cledionor Francisco de Mendonça Júnior ${ }^{1}$ \\ ESAM, C. Postal 137, 59625-900 Mossoró-RN; E-mail: fabiovsm45@hotmail.com; ${ }^{1 /}$ Estudante graduando em Eng. Agronômica
}

\begin{abstract}
RESUMO
O efeito do retardamento da colheita na qualidade e na vida útil dos frutos do meloeiro foi avaliado. Os frutos, tipo Honey Dew Orange Flesh, foram colhidos no dia adotado pelos produtores como maturidade comercial, um, dois, três e quatro dias após e, foram armazenados a $7 \pm 1^{\circ} \mathrm{C}$ e UR de $90 \pm 5 \%$. O experimento foi conduzido obedecendo delineamento inteiramente casualizado em esquema fatorial $5 \times 5$, com cinco repetições, cinco tempos de retardamento $(0 ; 1 ; 2 ; 3$ e 4 dias após o adotado para a colheita) e cinco tempos de armazenamento $(0 ; 7 ; 14 ; 21$ e 28 dias) após a colheita. Foram avaliado a aparência externa e interna, firmeza de polpa, conteúdo de sólidos solúveis e incidência de rachadura no pedúnculo. Foi observada perda gradativa de firmeza da polpa para todos os retardamentos durante o armazenamento. Ao final do experimento os frutos ainda apresentavam aparência própria à comercialização. O conteúdo de sólidos solúveis ficou entre 9 e $12 \%$ e a incidência de rachaduras foi menor para os frutos colhidos aos 59; 60 e 61 dias após o plantio.
\end{abstract}

Palavras-chave: Cucumis melo L., pós-colheita, vida útil, armazenamento.

\begin{abstract}
Effect of the harvest delay on the quality and post-harvest shelf-life Of orange Flesh melons

The effect of harvesting delay on quality and postharvest shelflife of Honey Dew Orange Flesh melons was examined. Fruits were harvested at the stage of commercial maturity and, one, two, three and four days after this period. Fruits were kept at $7 \pm 1^{\circ} \mathrm{C}$ and $90 \pm$ $5 \%$ relative humidity. A $5 \times 5$ factorial scheme in a completely randomized design with five replications was used, with five harvesting dates $(0 ; 1 ; 2 ; 3$ and 4 days after the stage of commercial harvest) and five storage periods $(0 ; 7 ; 14 ; 21$ and 28 days). During this period we evaluated the external and internal appearances, flesh firmness, soluble solid content and crack incidence of the peduncle. There occurred reduction of the flesh firmness for all harvest delaying dates. Fruits presented appropriate marketing appearance until the end of the experiment. The soluble solids content varied from 9 to $12 \%$, and the cracking incidence was smaller on fruits harvested at 59; 60 and 61 days after planting date.
\end{abstract}

Keywords: Cucumis melo L., postharvest, shelf-life, storage.

(Recebido para publicação em 27 de julho de 2002 e aceito em 17 de outubro de 2003)

$\mathrm{O}$ Rio Grande do Norte possui condições edafoclimáticas que favorecem a cultura do meloeiro, e a cada ciclo que passa vem aumentando a área plantada com o Orange Flesh, devido às suas características apreciadas tanto pelo produtor, como a produtividade, valor comercial do fruto, boa vida póscolheita, e pelo mercado consumidor, por ter um agradável flavor, coloração atrativa de casca e polpa e sabor característico.

O melão em 2000 contribuiu com $6,77 \%$ (US\$ 25 milhões) do total arrecadado com as exportações de frutos no Brasil (SECEX/MDIC, 2001). A região Nordeste em 1998 respondeu por 95\% (169 milhões de frutos) da produção total de melão do Brasil (Agrianual, 2001). Com o advento da irrigação, o estado do Rio Grande do Norte vem se constituindo em um dos principais polos exportadores de frutas tropicais, em especial o melão, sendo o principal produ- tor brasileiro com 64,98\% (116 milhões de frutos) da produção em 1998 (Agrianual, 2001).

Não tem sido documentados a firmeza de polpa média, o teor de sólidos solúveis totais e a aparência necessária para a colheita do melão Orange Flesh. A determinação de padrões é de suma importância e visa estabelecer critérios físico-químicos que possam viabilizar um sistema de controle de qualidade pós-colheita. $\mathrm{O}$ estabelecimento desses padrões de qualidade permitirá decisões no sentido de prever o comportamento pós-colheita desses frutos, o que pode ajudar os produtores. A qualidade dos frutos para o mercado Europeu está ligada diretamente ao teor de sólidos solúveis e aparência do fruto (Ena, 1997). Para que os frutos atinjam os requisitos necessários de exportação, devem ser colhidos na época certa, afim de que desenvolvam todas as características apreciadas e ainda apresentem uma fir- meza de polpa que suporte o transporte até o mercado consumidor (Menezes et al., 1995). Para Filgueiras et al. (2000), a colheita é o momento mais importante do processo produtivo e independe do melão plantado. Portanto, devem ser avaliados o teor de sólidos solúveis totais, a cor, aspecto da casca e a firmeza da polpa. Para Gomes Junior et al. (2001) as principais variáveis na determinação da qualidade pós-colheita de melão são o teor de sólidos solúveis, firmeza da polpa, perda de peso e aparências externa e interna: a firmeza da polpa fornece indicação sobre a vida útil pós-colheita e as outras características estão diretamente ligadas à aparência do produto, e conseqüentemente sua aceitação pelo consumidor.

Em melões, o conteúdo de açúcares é diretamente relacionado ao tempo que os frutos permanecem ligados à planta; por outro lado, o estádio de maturação é inversamente proporcional ao tempo 
de conservação pós-colheita (Welles e Buitelaar, 1988). Portanto, para manter a boa qualidade, é necessário colher frutos em estádio de maturação que possibilite maior tempo de prateleira. Conhecendo-se o tempo que o fruto pode ser mantido no campo sem perda da qualidade ou firmeza, os produtores podem trabalhar com boa margem de segurança contra imprevistos na colheita, distribuição e comercialização.

Os melões Honey Dew sob temperatura de $10^{\circ} \mathrm{C}$ e umidade relativa de 85 a $90 \%$, alcançam vida máxima de transito de 20 a 28 dias (Vallespir, 1997). Fernandes (1996) observou que os melões Honey Dew Orange Flesh, armazenados em temperaturas de $6^{\circ} \mathrm{C}$, após 14 dias apresentavam sintomas que se assemelhavam a injúria pelo frio. Vallespir (1997) também informa que a temperatura para a conservação de melões do grupo inodorus, como é o caso do Orange Flesh, deve estar entre 7 e $10^{\circ} \mathrm{C}$.

No presente trabalho propôs-se avaliar a vida útil do melão Orange Flesh submetido ao retardamento na sua colheita, e ao armazenamento refrigerado.

\section{MATERIAL E MÉTODOS}

Frutos da cultivar AF-1749, recomendados para o mercado externo, foram obtidos de um plantio experimental (Fazenda São João em Mossoró/ Assu), produzidos de acordo com as práticas culturais usuais da região, com sistema de irrigação localizada. O solo da área é um Latossolo Vermelho-Amarelo. O clima da região é quente e seco, com precipitação pluviométrica anual de $423 \mathrm{~mm}$ e temperatura média mensal $31^{\circ} \mathrm{C}$.

A cultivar AF-1749, comercializada pela Agroflora-Sakata, caracteriza-se pela boa aparência dos frutos de coloração de polpa salmão, casca creme, flavor peculiar, peso médio de 1,5 a $1,8 \mathrm{~kg}$, formato arredondado, pequena cavidade de sementes, conteúdo de sólidos solúveis entre 11 e $13 \%$, polpa macia e firme.

$\mathrm{O}$ experimento foi conduzido em delineamento inteiramente casualizado, em cinco repetições, no esquema fatorial 5 X 5, onde foram avaliados cinco tem- pos de retardamento da colheita $[59 ; 60$; $61 ; 62$ e 63 dias após o plantio, equivalendo ao dia indicado pelo produtor (dia $0 ; 1 ; 2 ; 3$ e 4 , respectivamente)] e cinco datas de análise $(0 ; 7 ; 14 ; 21$ e 28 dias de armazenamento), totalizando 25 tratamentos, com 3 frutos por repetição em duplicata. A colheita aos 59 dias após o plantio foi considerada como tratamento testemunha. A determinação do ponto de colheita é feita com base nos dias após o plantio, na coloração da casca, na amostragem do teor de sólidos solúveis e na observação do destacamento do pedúnculo. Os frutos foram conduzidos ao laboratório de pós-colheita da ESAM, onde foram selecionados, pesados e refrigerados imediatamente a $7 \pm$ $1^{\circ} \mathrm{C}$ e umidade relativa de $95+5 \%$. Dois dias antes de cada análise os frutos foram retirados das câmaras frias para simular as condições do mercado consumidor, onde o fruto permanece nas gôndolas por cerca de dois dias antes de ser comprado.

As avaliações de aparência externa (depressões, murcha ou lesões fúngicas) e aparência interna (colapso interno, sementes soltas ou presença de líquido) foram feitas segundo a classificação utilizada por Gomes Júnior et al. (2000) ( $1=$ fruto extremamente marcado pelos defeitos anteriormente destacados; 2=severo; 3=médio; 4=leve; 5=ausência dos defeitos). Frutos com nota $\leq 3,0$, foram considerados indesejáveis para o consumo e eliminados das análises. A firmeza da polpa foi obtida por duas leituras na parte mediana, em cada metade do fruto, com penetrômetro McCormick, modelo FT 327 com plunger de $8 \mathrm{~mm}$ de diâmetro, sendo os resultados obtidos em libras (lbf) e transformados para Newton (N). O teor de sólidos solúveis (SS) foi obtido com refratômetro digital, modelo PR-100 Palette, com correção automática de temperatura, utilizando-se suco filtrado e anotando-se em porcentagem, conforme Kramer (1973). A incidência de rachadura no pedúnculo foi obtida por observação visual dos frutos armazenados e daqueles separados para análise (foram contados a cada dia de análise anotandose a porcentagem em relação ao total de frutos armazenados), e esse valor foi cumulativo para os demais tempos.
Os resultados foram submetidos à análise de variância através do software SAS (Statistical Analisys Systen). Obtendo-se interação significativa, procedeu-se a análise de regressão por meio dos procedimentos PROC GLM e PROC REG.

\section{RESULTADOS E DISCUSSÃO}

Para aparência externa e interna não foram verificadas interações significativas mas sim, constância nas médias das avaliações. Os frutos de todos os tratamentos apresentaram média superior a 4, indicando condições adequadas para a comercialização (Figura 1). São considerados principais fatores de perda de qualidade na aparência externa o murchamento, surgimento de manchas escuras e amarelecimento da casca que se torna mais aparente no final do período experimental. Para a aparência interna, a perda de qualidade, caracteriza-se pela presença de colapso interno na polpa do fruto, aparecimento de sementes soltas e desintegração da placenta onde se encontram as sementes. Mendonça et al. (2002) trabalhando com a mesma cultivar colhida em diferentes cortes, verificou comportamento semelhante tanto para aparência externa como interna, tendo ao final de 28 dias de armazenamento, valores médios para ambas as características superior a três. O decréscimo gradual na aparência durante o tempo de armazenamento é normal e já foi verificado por vários autores estudando o melão amarelo 'Gold Mine' (Menezes et al., 1995; Dantas, 2000) e com os melões 'AF-646' e 'Rochedo' (Gomes Júnior, 2000).

Houve interação significativa para firmeza de polpa, onde se verificou um decréscimo gradativo com o decorrer do período de armazenagem. Verificou-se que ao final de 21 dias de armazenamento, apenas os tratamentos colhidos aos 59; 60 e 61 dias após o plantio obtiveram valores médios para firmeza igual ou superiores a $30 \mathrm{~N}$ (Figura 2). Acredita-se que o amolecimento da polpa do melão pode estar relacionado com a perda de membranas das células do mesocarpo, diminuindo a atividade da pectinametilesterase durante o armazenamento (Menezes et al., 1995). Fernan- 
des (1996), avaliando o melão Orange Flesh verificou decréscimo gradual na firmeza da polpa durante o tempo de armazenamento. Mendonça et al. (2001) trabalhando com melão Orange Flesh, verificou também decréscimo gradativo em função do tempo, de 39,35 N para $21,87 \mathrm{~N}$, respectivamente do início aos 28 dias de armazenamento. Gomes Júnior (2000), trabalhando com os genótipos 'AF-646' e 'Rochedo' sob armazenamento refrigerado também verificou a queda gradativa nos valores de firmeza de polpa.

Não foi verificada variação significativa no teor de sólidos solúveis, para a interação entre os tratamentos. Observou-se constância nos seus valores médios até o $14^{\circ}$ dia, e a partir daí uma tendência de diminuir (Figura 3), com valores entre 9 e $12 \%$, ideais para a comercialização no mercado externo (Gayet, 1994). Menezes et al. (1998) reportam que são desejáveis valores superiores a $9 \%$, em virtude dos SS serem uma importante característica de qualidade do ponto de vista comercial. Durante o armazenamento observou-se variação decrescente na curva, provavelmente pela heterogeneidade dos frutos. Mesmo apresentando decréscimo, as médias foram mantidas dentro do intervalo descrito por Gayet (1994). Em geral não se verifica variações consideráveis no teor de SS durante o armazenamento de melões devido à inexistência de amido para a conversão em açúcares solúveis (Tucker, 1993). O decréscimo no teor de SS pode ser atribuído ao consumo de carboidratos pela respiração. O armazenamento refrigerado diminui a perda de massa pela respiração pelo menor metabolismo do fruto, mas a perda excessiva de água, devido a baixas umidades, pode afetar a respiração aumentando a perda de massa e conseqüentemente o consumo de carboidratos. Menezes et al. (1995) tiveram como resultados do armazenamento de melão 'AF-646' a uma temperatura de \pm $25^{\circ} \mathrm{C}$, um decréscimo de 10,07 (0 dia) a 8,10 (49 dias), que foi considerado relativamente constante.

Verificou-se que os tratamentos colhidos dos 59 aos 61 dias após o plantio não apresentaram rachaduras até o $14^{\circ}$ dia de armazenamento. Frutos colhidos

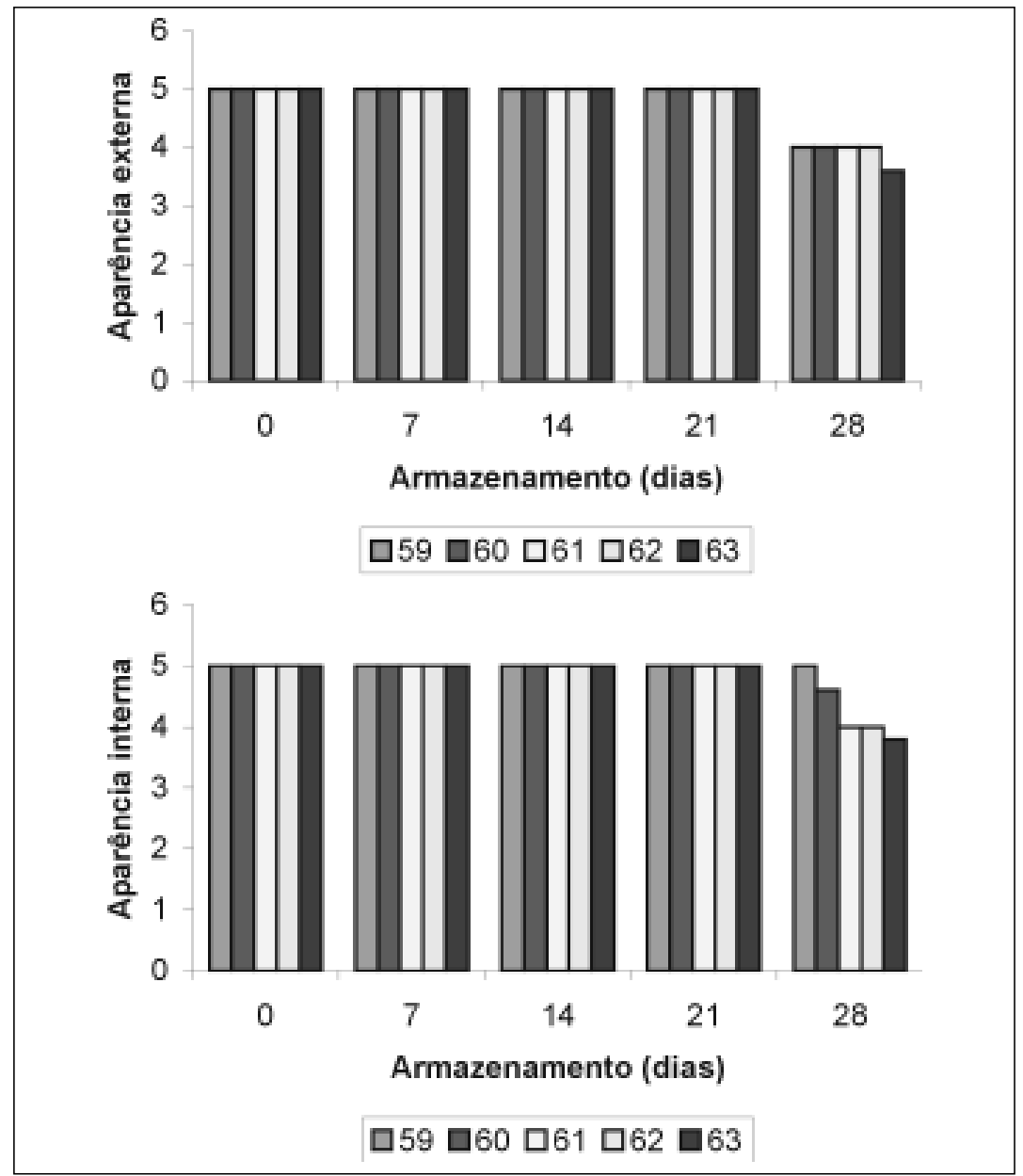

Figura 1. Valores médios de aparência externa (A) e interna (B) do melão Orange Flesh 'AF-1749', colhido em cinco datas após o plantio: 59;60;61; 62 e 63. Armazenados à temperatura de $7 \pm 1^{\circ} \mathrm{C}$ e umidade relativa de $90 \pm 5 \%$. Mossoró, ESAM, 2001.

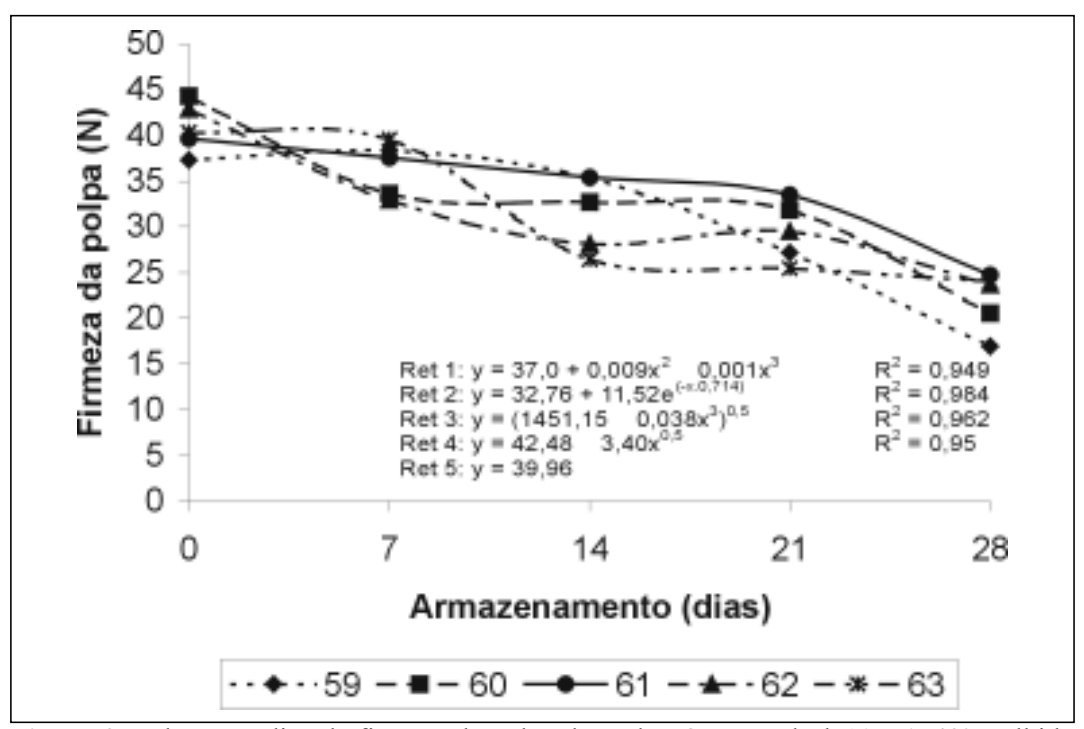

Figura 2. Valores médios da firmeza de polpa do melão Orange Flesh 'AF-1749', colhido em cinco datas após o plantio: 59;60;61;62 e 63. Armazenados à temperatura de $7 \pm 1^{\circ} \mathrm{C} \mathrm{e}$ umidade relativa de $90+5 \%$. Mossoró, ESAM, 2001 . 


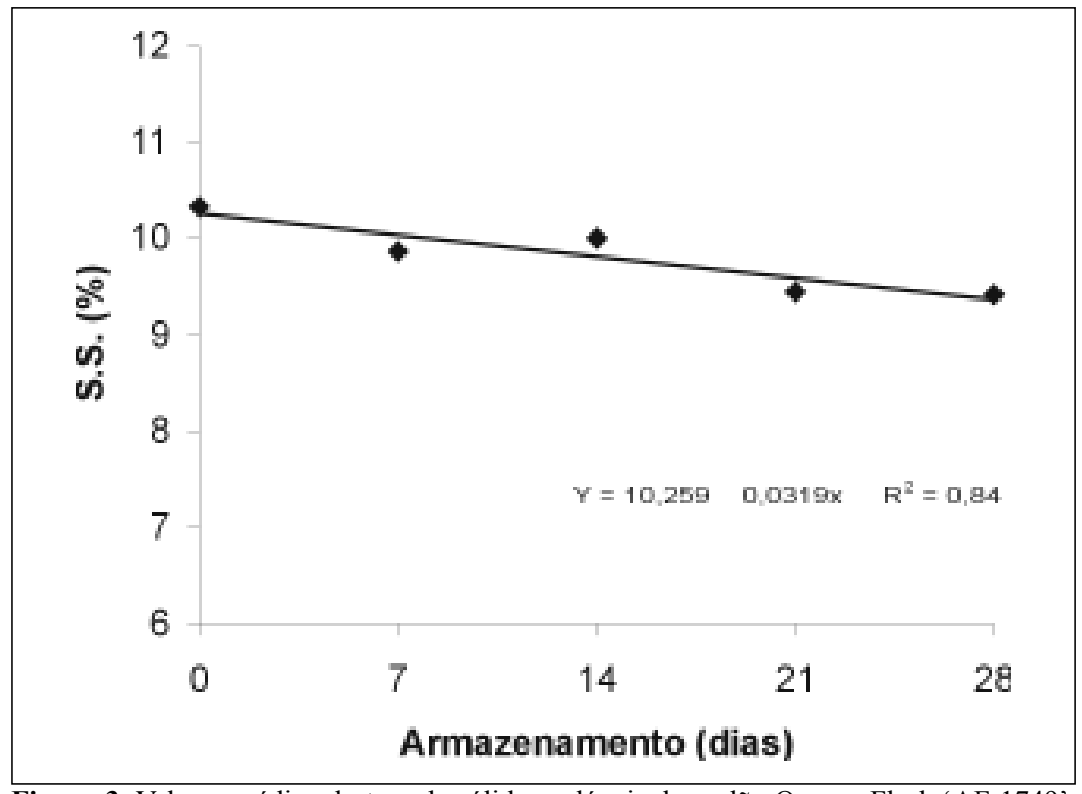

Figura 3. Valores médios do teor de sólidos solúveis do melão Orange Flesh 'AF-1749', colhido em cinco datas após o plantio, durante o tempo armazenamento à temperatura de 7 $\pm 1^{\circ} \mathrm{C}$ e umidade relativa de $90 \pm 5 \%$. Mossoró, ESAM, 2001

aos 62 e 63 dias já apresentavam incidência de rachaduras no pedúnculo, do $7^{\circ}$ ao $14^{\circ}$ dia de armazenamento, no entanto, não comprometendo sua qualidade visual. Mendonça et al. (2001), trabalhando com melão Orange Flesh, verificaram que os frutos maduros armazenados imediatamente após a colheita a $7^{\circ} \mathrm{C}$, ao final de 28 dias atingiram $5,5 \%$ de frutos com incidência de rachadura. Mesmo colhendo aos 62 e 63 dias após o plantio, a quantidade de frutos com rachadura no pedúnculo não influenciou a aparência externa ou interna dos frutos, possibilitando sua comercialização.

Com base nos resultados obtidos, pode-se considerar que os frutos de melão Honey Dew Orange Flesh podem ser armazenados por até 28 dias, podendo nesse intervalo ser comercializados sem nenhum problema de aparência, possibilitando a sua exportação principalmente para o mercado europeu. A firmeza da polpa aos 21 dias de armazamento foi superior para os tratamentos colhidos dos 59 aos 61 dias após o plantio, não impossibilitando a comercialização dos frutos colhidos aos 62 e 63 dias após o plantio. Associan-
FILGUEIRAS, H.A.C.; MENEZES, J.B.; ALVES, R.E.; COSTA, F.V.; PEREIRA, L.S.E.; GOMES JUNIOR, J. Colheita e manuseio póscolheita. In: ALVES, R.E. (Org.). Melão pós-colheita. Brasília, Frutas do Brasil, 2000. p.23-41.

GAYET, J.P. Características das frutas de exportação. In: NETO, A.G., Melão para a exportação: procedimento colheita e pós-colheita. Brasília, MAARA/FRUPEX, 1994. p.11-21.

GOMES JÚNIOR, J. Suscetibilidade a danos pelo frio de melóes amarelos 'AF-646' $e$ 'Rochedo'. 2000. 42 p. (Tese mestrado), ESAM, Mossoró. GOMES JÚNIOR, J.; MENEZES, J.B.; SOUZA, P.A.; GUIMARÃES, A.A.; SIMÕES, A.N. Armazenamento refrigerado de melão 'Hy Mark'. Horticultura Brasileira. Brasília, v. 18, 2000. Suplemento. Trabalho apresentado no $40^{\circ}$ Congresso Brasileiro de Olericultura, 2000.

GOMES JÚNIOR, J.; MENEZES, J.B.; NUNES, G.H.S.; COSTA, F.B. SOUZA, P.A. Qualidade pós-colheita de melão tipo cantaloupe, colhido em dois estádios de maturação. Horticultura Brasileira. Brasília, v.19, n.3, p.356-360, 2001.

KRAMER, A. Fruits and Vegetables. In: KRAMER, A.; TWIGG, B.A. Quality Control for the Food Industry. Connecticut: Avi Publishing Company, 1973. v.2, p.157-227.

MENDONCA, F.V.S.; MENEZES, J.B.; GOMES JUNIOR, J.; SOUZA, P.A.; NUNES, G.H.S.; SENHOR, R.F. Influência da rachadura de pedúnculo de melão Orange Flesh, durante o armazenamento refrigerado. Horticultura Brasileira, Brasília, v. 19, 2001. Suplemento. CD-Room. Trabalho apresentado no $41^{\circ}$ congresso Brasileiro de Olericultura, 2001.

MENDONÇA, F.V.S.; MENEZES, J.B.; GOIS, V.A.; TORRES, M.M.; NUNUES, G.H.S. Vida útil pós-colheita do melão (Cucumis melo L.) Orange Flesh de diferentes cortes, sob armazenamento refrigerado. Horticultura Brasileira, Brasília, v.20, n.2, 2002. Suplemento2. CD-Room. Trabalho apresentado no $42^{\circ}$ congresso Brasileiro de Olericultura, 2002.

MENEZES, J.B.; CHITARRA, A.B.; CHITARRA, M.I.F.; CARVALHO, H.A. Caracterização pós-colheita do melão amarelo 'AF646'. Horticultura Brasileira, Brasília, v.13, p.150-153, 1995.

SECEX/MDIC. Secretaria de Comércio Exterior/ Ministério do Desenvolvimento, Indústria e Comércio. Exportações Brasileiras de Frutas. Disponível em: <http:www.mdic.gov.br>. Acesso em 19/05/01.

TUCKER, G.A. Introduccion. In: SEYMOR, G.B.; TAYLOR, S.E., TUCKER, G.A. Biochemistry of fruits ripening. London: Chapman \& Hall, 1993. p.255-266.

WELLES, G.W.H.; BUITELAAR, K. Factors affecting soluble solids content of muskmelon (Cucumis melo L.). Netherlands Journal of Agricultural Science. v.36, p.239-246, 1988.

VALLESPIR, A.N. Melón, In: Post-recoleccion de Hortalizas. Reus, Ediciones de Horticultura, S. L., 1997. p.147-179 